\title{
O PODER DO PODER DE POLÍCIA À LUZ DO DIREITO SANITÁRIO E DA VIGILÂNCIA SANITÁRIA
}

THE POWER OF POLICE POWER IN THE LIGHT OF HEALTH LAW AND HEALTH SURVEILLANCE

EL PODER DEL PODER DE POLICÍA A LA LUZ DEL DERECHO SANITARIO Y DE LA VIGILANCIA SANITARIA

Antônio Augusto Vieira de Aragão ${ }^{1}$

Sydia Rosana de Araújo Oliveira ${ }^{2}$

Palavras-chave: Vigilância Sanitária; Poder de Polícia; Saúde Pública.

Keywords: Health Surveillance; Police Power; Public Health.

Palabras clave: Vigilancia Sanitaria; Poder de Policía; Salud Pública.

Submetido: $14 / 12 / 2017$

Aprovado: 26/04/2018

Autor(a) para Correspondência: Antônio Augusto Vieira de Aragão End: Rua das Acácias SN, São Cristovão - CEP-56.512-380, Arcoverde-PE E-mail:augustoapevisa@gmail.com

\section{RESUMO}

Em virtude da vigilância sanitária (Visa) assumir caráter prioritário e compreender um conjunto de instituições do setor saúde cuja finalidade é controlar riscos provenientes dos processos produtivos, este artigo discorre sobre suas atribuições quando dotada do chamado poder de polícia, à luz do direito sanitário. Apresentam-se definições de poder, direito sanitário, poder de polícia e a abrangência desses termos, além de indicar a função do Poder Judiciário como mecanismo de controle da atividade pública. Aborda-se a inter-relação do poder de polícia com a saúde pública, porém, é na execução de suas funções na Visa que recebe seu direcionamento e suas responsabilidades. Observa-se que a Visa busca executar suas ações com ética e eficácia, com vistas à construção de uma sociedade dimanante e justa. Por ser um tema de natureza complexa, mostra-se imperativo apontar que o pleno exercício do poder de polícia, por ser de interesse público, demanda compartilhamento e transparência em suas ações, bem como compromisso e responsabilidade social, para gerar credibilidade diante da população.

1. Médico veterinário graduado pela Universidade Federal Rural de Pernambuco (UFRPE). Especialista em Saúde Pública pela Universidade de Pernambuco (UPE). Mestre em Saúde Pública pelo Instituto Aggeu Magalhães da Fundação 0swaldo Cruz (IAM/Fiocruz). Aluno de Doutorado em Saúde Pública no IAM/Fiocruz. Fiscal sanitário da Agência Pernambucana de Vigilância Sanitária (Apevisa). Recife (PE), Brasil. E-mail: augustoapevisa@ gmail.com

2. Dentista. Mestre em Saúde Comunitária. Doutora em Saúde Pública. Analista de Gestão em Saúde no IAM/ Fiocruz. Recife (PE), Brasil. E-mail: sydia@cpqam.fiocruz.br 


\section{ABSTRACT}

Since the Brazilian health surveillance (VISA) is a priority and a set of institutions in the health sector whose purpose is to control risks arising from productive processes, this article discusses its attributions when endowed with the so-called police power in the light of health law. Definitions of power, health law, and police power, and the scope of these terms are presented, as well as the Judiciary's role as a mechanism for controlling the public activity is indicated. We address the interrelationship between police power and public health, however, it is in the execution of its functions within the VISA that its direction and its responsibilities are received. It is noticed that the VISA seeks to carry out its actions ethically and effectively, with a view to building a fair and forthcoming society. Because this is a complex theme, it is imperative to point out that the full exercise of police power, as an issue of public interest, requires sharing and transparency in its actions, as well as commitment and social responsibility, in order to generate credibility vis-à-vis the population.

\section{RESUMEN}

Dado que la vigilancia sanitaria brasileña (VISA) es una prioridad y un conjunto de instituciones en el sector salud cuyo objetivo es controlar riesgos derivados de los procesos productivos, este artículo discurre acerca de sus atribuciones cuando está dotada del llamado poder de policía a la luz del derecho sanitario. Se presentan las definiciones de poder, derecho sanitario y poder de policía, y el alcance de estos términos, además de indicar la función del Poder Judicial como mecanismo de control de la actividad pública. Se aborda la interrelación entre el poder de policía y la salud pública, sin embargo, es en la ejecución de sus funciones dentro de la VISA donde se reciben su dirección y sus responsabilidades. Se observa que la VISA busca llevar a cabo sus acciones de manera ética y efectiva, con el objetivo de construir una sociedad dimanante y justa. Debido a que este es un tema complejo, es imperativo señalar que el pleno ejercicio del poder de policia, como cuestión de interés público, requiere compartición y transparencia en sus acciones, así como compromiso y responsabilidad social, a fin de generar credibilidad ante la población.

\section{INTRODUÇÃO}

Este artigo discorre sobre as atribuições da vigilância sanitária (Visa) quando dotada do chamado poder de polícia, à luz do direito sanitário. Apresentam-se definições de poder, direito sanitário, poder de polícia e a abrangência desses termos, além de indicar a função do Poder Judiciário como mecanismo de controle da atividade pública. A Visa, de caráter prioritário, compreende um conjunto de instituições do setor saúde cuja finalidade é controlar riscos provenientes dos processos produtivos.

0 poder é um conceito amplo, que envolve a capacidade de produzir ou contribuir para resultados que influenciam de modo considerável o(s) outro(s) por meio de relações sociais ${ }^{1}$. É intercambiável e utilizável como recurso para viabilizar planos. Consequentemente, o homem coletivo, como ator desses planos, deve expressar a consciência social do indivíduo - cada homem é um legatário e governante de seus atos, o que edifica sua liberdade ${ }^{2}$.

0 desenvolvimento dos centros urbanos, junto com a crescente complexidade cultural, religiosa e econômica das sociedades, trouxe a lume uma forma de organização social e política: o Estado. Neste, o direito assumiu relevância estratégica: ele ordena 0 jogo político das populações, as estruturas de organização do aparato estatal e as condições de exercício do poder. 0 Estado sistematiza suas ação e detém o monopólio do uso da força, condicionando todos os indivíduos a uma miríade pré-determinada de normas (e as respectivas sanções se não forem cumpridas) ${ }^{3}$.

Definir o termo saúde é algo de uma importância nesse contexto. 0 conceito de saúde é pauta de discussão desde os filósofos da Grécia Antiga, quando estava relacionado ao meio ambiente habitado pelo homem e à ausência de doenças. Em meados do século $X X$, com a organização política internacional pósSegunda Guerra Mundial e com a criação da Organização Mundial da Saúde (OMS), em 1946, a saúde foi reconhecida como direito fundamental de todo ser humano, sem diferenciação de raça, credo religioso, posição política ou condição econômica ou social - refere-se ao bem-estar físico, mental e social como um todo e não se limita à ausência de doenças ou outros agravos ${ }^{4}$.

A saúde constitui um ramo didaticamente autônomo do direito positivo, com diretrizes que aludem, direta ou indiretamente, à relação triádica entre Estado, sociedade e saúde pública ${ }^{5}$.

Duas designações são atribuídas a essa disciplina 
jurídica: direito sanitário e direito da saúde. 0 vocábulo sanitário provém do francês sanitaire, relativo a saúde e higiene. E a expressão da saúde aponta o objeto ou bem jurídico tutelado. No Brasil, predomina o termo direito sanitário, entendido como o conjunto de normas jurídicas reguladoras do poder de polícia voltado à promoção, proteção e recuperação da saúde, bem como à organização e ao funcionamento dos serviços de saúde ${ }^{4}$.

Assim, diferencia-se o direito sanitário do direito da saúde, cujo objeto é mais amplo e complexo. Nessa lógica, o direito da saúde constitui uma intersecção entre o direito positivo e o setor saúde (com serviços públicos e privados) - que engloba todos os aspectos relacionados à vida, ao bem-estar físico e mental e ao controle das doenças. 0 direito sanitário tem um objeto mais restrito: consiste no controle, viabilizado pelo poder de polícia, de todas as atividades públicas e privadas com potencial repercussão na saúde pública ${ }^{5}$.

$\mathrm{Na}$ Constituição Federal de 1988 (CF/1988), o direito da saúde é reconhecido como direito social (artigo $6^{\circ}$ ) e direito de todos (artigo 196), dotado de normas jurídicas que disciplinam as circunstâncias que têm a saúde por objeto mediato ou imediato; tais normas regulam a organização e o funcionamento das instituições destinadas à promoção da saúde ${ }^{6}$. Vale enfatizar que o vocábulo direito não denota apenas o ordenamento jurídico, podendo referir-se ao caminho para constatar a legitimidade dos atos e às permissões derivadas de normas jurídicas (o chamado direito subjetivo $)^{7}$.

0 Poder Judiciário tem assumido papel de destaque no Brasil quanto à garantia do direito à saúde, o que propicia uma análise complexa e fundamentada por parte de juristas, por afetar a operacionalização das políticas de saúde ${ }^{8}$.

Este artigo tem por objetivo demonstrar que 0 exercício do poder de polícia sempre deve ter o interesse público como razão.

\section{METODOLOGIA}

Este estudo descritivo adotou a revisão de literatura como técnica e baseia-se em material bibliográfico, como: obras de doutrina jurídica, legislação e jurisprudência; e periódicos científicos disponiveis nas bases eletrônicas SciELO e BVS (buscas no período de abril de 2017 a abril de 2018).

Apresentam-se concepções, características, competências e limites do poder de polícia, abordando

\section{A policia materializa \\ a prerrogativa de que \\ a administração \\ pública pode \\ restringir e \\ condicionar o uso e \\ gozo de bens...}

sua inter-relação com a saúde pública, bem como seu direcionamento e suas responsabilidades com base na Visa, com a finalidade de destacar sua abrangência em prol do exercício dos direitos individuais e do bem-estar social.

\section{RESULTADOS E DISCUSSÃO}

\section{Concepções e abrangência do poder de polícia}

0 ordenamento jurídico brasileiro, desde a CF/1988 até as leis infraconstitucionais, concede, confere e outorga uma série de direitos relacionados à propriedade e é uníssono na doutrina jurídica que o uso, o gozo e a disposição da propriedade estão vinculados precisamente à função social da propriedade - instrumento adequado para restringir os abusos da propriedade e do gozo, da disposição e do exercício da liberdade. Assim, o exercício do poder de polícia não pode afrontar o direito, porque comumente é um ato infraconstitucional mediado por um ato administrativo ${ }^{9}$.

A polícia é uma organização administrativa derivada do vocábulo latino politia, refere-se a "governo de uma cidade", "cidadania”, "administração pública" ou "política civil". Sua responsabilidade é impor limitações à liberdade (individual ou coletiva), na exata medida necessária à salvaguarda e manutenção da ordem pública (mais do que o considerado necessário constitui abuso do poder de polícia $)^{10}$. Pode-se dizer que a polícia é a instituição com legitimidade para o uso da força quando algo afronta a ordem pública e há necessidade de uma resposta do poder público ${ }^{11}$.

No Brasil, a polícia age em cumprimento do que dispõe a lei - de forma discricionária, segundo o entendimento do agente público, cabendo ao Poder Judiciário analisar os casos de abuso do poder de polícia. A polícia materializa a prerrogativa de que a administração pública pode restringir e condicionar o 
uso e gozo de bens, atividades e direitos individuais em benefício da coletividade ${ }^{12}$.

A administração pública atribui a serviços e corporações com legitimidade e capacitação específicas a manutenção da ordem pública, em conformidade com a legislação aplicável, em todas as áreas que demandem ação nesse sentido, com uso de meios e instrumentos legais, aplicados na defesa do que for individual, particular ou coletivo, corporal ou patrimonial ${ }^{13}$. 0 objetivo é preservar a ordem pública com medidas restritivas aos direitos individuais que se mostrem necessárias à salvaguarda da moralidade, da propriedade, da saúde pública e do exercício da liberdade em conformidade com a legislação aplicável ${ }^{14}$.

Polícia é o termo genérico que designa a força organizada que ampara a sociedade livrando-a da chamada vis inquietativa. Sua finalidade é assegurar a tranquilidade, a segurança e a salubridade no âmbito da sociedade ${ }^{15}$.

Atualmente, todo o sistema de proteção de um Estado de direito tem o tríplice objetivo de assegurar a tranquilidade, a segurança e a salubridade pública e caracteriza-se pela competência de adotar medidas que visem a tal desideratum. Trata-se da faculdade discricionária da administração pública de limitar as liberdades individuais em prol do interesse coletivo - nos termos da lei ${ }^{16}$.

Somente o Estado, como legislador, pode limitar e condicionar liberdades e direitos; assim, o poder de polícia, como aplicação da lei, é exercido pelo Estado, como administrador ${ }^{17}$.

Adotando uma conotação ampla, o termo polícia também pode ser definido como ação da administração pública que, ao limitar ou disciplinar liberdades e direitos, regulamenta a prática de ato ou a abstenção de fato em prol do interesse público relativo a segurança e tranquilidade pública, higiene, costumes, propriedade, produção e mercado e direitos individuais ou coletivos. 0 exercício do poder de polícia é considerado regular quando executado pelo órgão competente nos limites da lei aplicável, com observância do processo legal e sem abuso ou desvio de finalidade ${ }^{18}$.

São atributos gerais da polícia: a) discricionariedade; b) autoexecutoriedade; e c) coercibilidade ${ }^{11}$. A polícia tem um atributo específico; trata-se de uma atividade negativa, no sentido de que a atividade positiva proporciona um benefício material ou objetivo aos cidadãos - por exemplo, a energia elétrica ${ }^{19}$. Em outras palavras, com o poder de

\section{...o poder de \\ polícia, como \\ aplicação da lei, é \\ exercido pelo \\ Estado, como \\ administrador.}

polícia, a administração pública coíbe a prática de determinados atos contrários ao interesse público como determina a obrigação de não fazer, constitui uma atividade negativa ${ }^{11,20}$.

0 poder de polícia cabe àqueles que detêm efetivamente a competência para seu exercício, constituindo um ato administrativo. Mesmo que o poder de polícia não possa ter sua ilegalidade aferida diretamente pela letra da lei constitucional ou infraconstitucional, deve-se submetê-lo objetivamente a outros princípios quanto à sua razoabilidade para avaliar uma tutela indireta ou oblíqua da ilegalidade 9 . 0 poder de polícia encontra limites na legislação que tem por objeto a atividade policial (em especial na CF/1988) e não se descarta o exame de casos concretos para determinar se seu exercício é razoável.

Assim, nos termos da CF/1988, a competência limita o exercício do poder de polícia. Como não existe hierarquia entre as entidades componentes da Federação, exceto em campos diferentes de atuação, dispõe-se a competência para o exercício do poder de polícia no âmbito territorial de cada esfera de governo - se o órgão não for competente, o ato não terá legitimidade ${ }^{18}$.

0 conceito atual de poder de polícia garante ao Estado um papel mais ativo na promoção do bemestar de todos. A legislação não dispõe apenas no tocante à ordem pública, mas sobretudo no sentido da manutenção da ordem social e econômica, com normas limitadoras da liberdade individual operacionalizadas predominantemente por meio do poder de polícia ${ }^{21}$. Mostra-se fundamental considerar que o exercício do poder de polícia deve acatar os seguintes limites ${ }^{22}$ :

1. Necessidade: como medida administrativa, a polícia deve ser adotada apenas para evitar ameaças prováveis ou reais ao interesse público. 0s interesses individuais não podem contrastar com o interesse público, sobretudo quando se trata da proteção à saúde pública ${ }^{22}$. Por exemplo: uma indústria emite poluentes em um de seus setores. 0 órgão de 
fiscalização define prazo para a colocação de filtros na primeira visita. Na segunda visita, aplica multa por meio de auto de infração - a ação é necessária, pois a empresa fere o interesse público.

2. Proporcionalidade: os meios utilizados têm a obrigação de ser proporcionais aos fins visados. Se não forem proporcionais, constituem abuso de poder ${ }^{22}$. Por exemplo: no mesmo episódio, não ocorrendo o pagamento da multa e persistindo a emissão de poluentes, o órgão de fiscalização interdita toda a empresa. Essa medida pode ser desproporcional no caso de ser possivel interditar apenas o setor da empresa responsável pela poluição. Então, caberá à autoridade sanitária estabelecer, discricionariamente, nos limites da lei, a medida pertinente.

3. Eficácia: a medida deve ser adequada para evitar o dano ao interesse público 22 . Por exemplo: no mesmo caso, em vez de interditar, o órgão fiscalizador aplica nova multa. Continuam a ser emitidos poluentes. Não adianta aplicar mais multas, pois elas não impedem o dano ao interesse público. Mostra-se oportuno adotar outra medida, como interditar o estabelecimento.

Como o poder é intercambiável, o homem coletivo deve reivindicar e estimular a consciência social de cada indivíduo para edificar e defender a liberdade. Tendo em vista que o princípio informador de poder é que autoriza a administração pública a condicionar ou restringir o exercício de direitos e atividades particulares, deve prevalecer o interesse público sobre o interesse privado². E o direito sanitário, parte do direito administrativo que disciplina o exercício da função sanitária dos entes públicos, tutela diretamente o interesse sanitário da coletividade.

Diante das concepções apresentadas e discutidas, conclui-se que o poder de polícia é a atividade do Estado que limita o exercício dos direitos individuais em benefício do interesse público. Para o exercício do poder de polícia, permite-se a utilização de medidas repressivas, desde que executadas com a finalidade de ajustar o comportamento individual à legislação pertinente.

\section{Inter-relação do poder de polícia com a saúde pública}

0 poder de polícia está presente em diversas áreas da saúde pública, mas é na execução de suas funções no âmbito da Visa que recebe seu direcionamento e suas responsabilidades. Há uma miríade de níveis que

\section{...o homem \\ coletivo \\ deve reivindicar e \\ estimular a \\ consciência \\ social...}

conferem características próprias à Visa, como a dimensão política, técnica, ideológica e jurídica. $0 \S$ $1^{\circ}$ do artigo $6^{\circ}$ da Lei n. 8.080/1990 dispõe sobre 0 conceito de Visa:

$\S 1^{\circ}$ Entende-se por vigilância sanitária um conjunto de ações capaz de eliminar, diminuir ou prevenir riscos à saúde e de intervir nos problemas sanitários decorrentes do meio ambiente, da produção e circulação de bens e da prestação de serviços de interesse da saúde ${ }^{23}$.

Verifica-se uma nítida ampliação da Visa nas três décadas de vigência da Lei n. 8.080/1990, passando a ter inter-relações com toda a cadeia de serviços de saúde e com o meio ambiente ${ }^{24}$.

Em geral, os Estados de direito organizam serviços no âmbito da Visa considerando o princípio da livre iniciativa e o motor da produção capitalista, ou seja, o lucro. É forçoso admitir a dificuldade de atuação no mercado por parte de todos os interessados em relação aos direitos uns dos outros e aos direitos dos cidadãos e consumidores. Assim, a Visa assume vital importância como instrumento de organização econômica da sociedade, pois sua função protetora abarca não só os cidadãos e consumidores, mas também os produtores, uma vez que agrega valor à produção ${ }^{3}$.

Destarte, as ações da Visa estão dispostas em um contexto mais abrangente, qual seja, o das ações de saúde, buscando a promoção, a prevenção e a recuperação da saúde - um dos direitos fundamentais dos indivíduos ${ }^{24}$.

A Visa faz parte do Sistema Único de Saúde (SUS), em cumprimento da CF/1988, assume caráter prioritário e suas ações têm natureza fundamentalmente econômica ${ }^{25-27}$. 0 trabalho desenvolvido em nível nacional pela Visa tem tornado - Brasil uma referência em regulação sanitária e econômica na América Latina, englobando produtos e serviços de saúde que representam $25 \%$ do produto interno bruto (PIB) do país. 


\section{Direcionamento com as responsabilidades da vigilância sanitária}

A Visa compreende um conjunto de instituições do setor saúde com a finalidade de controlar riscos provenientes de processos produtivos e engloba a normatização, regulação e fiscalização de produtos e serviços relacionados à saúde. Trata-se da configuração mais complexa da saúde pública, pois suas ações, eminentemente preventivas, perpassam todas as práticas médico-sanitárias e são de grande relevância no contexto da promoção, proteção e recuperação da saúde ${ }^{26,27}$.

Ressalta-se que as ações da Visa são educativas e normativas (exercício do poder regulamentar), contudo, seu poder de polícia assume destaque perante a população. A Visa tem numerosas atribuições e todas, sob a ótica da população, envolvem alta complexidade.

A regulação sanitária é um exercício de poder, por isso a Visa detém o chamado poder de polícia, limitando o exercício dos direitos individuais em benefício do interesse público. 0 poder é um atributo para o cumprimento do dever do Estado de proteger a saúde da população. Em busca da segurança sanitária, a Visa, como braço especializado do Estado para a regulamentação em saúde, deve recorrer a tecnologias de intervenção, informações, metodologias e estratégias afinadas com o conhecimento científico atualizado e os princípios estabelecidos pela CF $/ 1988^{3}$.

Com isso, observa-se uma miríade de normas nos diferentes ramos da Visa. Algumas dessas normas são de complexa execução em determinadas circunstâncias históricas e tecnológicas de localidades específicas do nosso país 22 .

0 exercício do poder de polícia sempre visa ao interesse público e a saúde, um bem inalienável, não deve encontrar barreiras quando se trata de sua promoção, proteção e recuperação $0^{9}$. Nesse contexto, a Visa busca cumprir suas responsabilidades de modo ético e eficaz, com vistas à construção de uma sociedade dimanante e justa, em uma relação harmônica com diferentes atores sociais ${ }^{24}$. Vale ressaltar que o poder de polícia não pode afrontar 0 direito constitucional e as ações da Visa se compatibilizam plenamente com os princípios da CF/1988.

\section{CONCLUSÃO}

Este estudo abordou as atribuições da Visa quando dotada do poder de polícia, à luz do direito sanitário. Por ser um tema de natureza complexa, vale ressaltar que o poder do pleno exercício do poder de polícia, de interesse público, demanda compartilhamento e transparência nas ações, bem como compromisso e responsabilidade social para gerar credibilidade diante da população. Constatou-se que a inter-relação do poder de polícia com a saúde pública recebe seu direcionamento e suas responsabilidades na execução das funções da Visa, que age com ética e eficácia no Brasil do século XXI.

\section{CONTRIBUIÇÃO DOS AUTORES}

Antônio Augusto Vieira de Aragão contribuiu com o delineamento e a realização da pesquisa e a redação e revisão crítica do manuscrito. Sydia Rosana de Araújo Oliveira contribuiu com a redação e revisão crítica do manuscrito.

\section{AGRADECIMENTO}

Os autores agradecem a Álvaro Lazzarini (in memoriam), Desembargador de Justiça do Estado de São Paulo, por seu alto senso de compromisso e responsabilidade social.

\section{REFERÊNCIAS}

1. Lukes SM. El poder. Un enfoque radical. Madrid: Siglo XXI; 2007.

2. Matus C. Política, planejamento e governo. 2. ed. Brasília (DF): Ipea; 1996. t. 1.

3. Aith F, Minhoto LD, Costa EA. Poder de polícia e vigilância sanitária no Estado democrático de direito. In: Costa EA, organizer. Vigilância sanitária: temas para debate. Salvador: Ed. UFBA; 2009. p. 37-60.

4. Rocha JCS. Direito sanitário na perspectiva dos interesses difusos e coletivos. 2. ed. São Paulo: Atlas; 2011. 
5. Carvalho C, Machado RB, Timm LB. Direito sanitário brasileiro. São Paulo: Quartier Latin; 2004.

6. Correia S. Introdução ao direito da saúde. In: Oliveira A, Rocha N, Raposo M, Monteiro S, Correia S, Martinez S, et al. Direito da saúde e bioética. Lisboa: Lex; 1991. p. 39-53.

7. Dallari SG. 0 direito sanitário como campo fundamental para a vigilância sanitária. In: Marques MCC, Carvalho ML, Silveira D, Castro PC, Ibañez N, organizers. Vigilância sanitária: teoria e prática. São Carlos (SP): RiMa; 2006. p. 15-32.

8. Vasconcelos FJL, Dias MAS, Saraiva MJG, Silva MMS. Judicialização da saúde: análise de ações judiciais demandadas na comarca de Sobral, Ceará. Sanare (Sobral, Online) [serial on the internet]. 2017 [cited $2018 \mathrm{Apr}$ 25];6(2):6-13. Available from: https://sanare.emnuvens. com.br/sanare/article/view/1172/633

9. Dias HP. Flagrantes do ordenamento jurídico-sanitário. Brasília (DF): Anvisa; 2000.

10. Lazzarini A. Estudos de direito administrativo. 2. ed. São Paulo: Revista dos Tribunais; 2008.

11. Di Pietro MSZ. Direito administrativo. 14. ed. São Paulo: Atlas; 2002.

12. Meirelles HL. Direito administrativo brasileiro. 27. ed. São Paulo: Malheiros; 2002.

13. Cartana AP. Processo administrativo sanitário: teoria e prática. Porto Alegre: Alcance; 2000

14. Silva DP. Vocabulário jurídico. 2. ed. São Paulo: Forense; 2002.

15. 15. Medauar 0. Direito administrativo moderno. 11. ed. São Paulo: Revista dos Tribunais; 2007.

16. Cretella Júnior J. Curso de direito administrativo. Rio de Janeiro: Forense; 2006.

17. Moreira Neto DF. Curso de direito administrativo. Rio de Janeiro: Forense; 2003

18. Brasil. Lei n. 5.172, de 25 de outubro de 1966. Dispõe sobre o Sistema Tributário Nacional e institui normas gerais de direito tributário aplicáveis à União, Estados e Municípios. Diário Oficial da União [serial on the internet], Brasília (1966 0ct 27 [cited 2018 Apr 25]);Sec.1. Available from: http://www.planalto.gov.br/ccivil 03/leis/15172.htm

19. Araújo AJB, Maciel TB. Curso de direito sanitário para inspetores da Apevisa. [S.l]: [s.n]; 2010. Não publicado.

20. Bandeira de Mello CA. Curso de direito administrativo. 26. ed. São Paulo: Malheiros; 2009.
21. Lazzarini A. Limites do poder de polícia. Justitia [serial on internet]. 1995 [cited 2018 Apr 25];57(170):73-85. Available from: http://www.revistajustitia.com.br/links/ revistas.php

22. Brasil. Manual de direito sanitário com enfoque na vigilância em saúde. Brasília (DF): Ministério da Saúde; 2006.

23. Brasil. Lei n. 8.080 , de 19 de setembro de 1990. Dispõe sobre as condições para a promoção, proteção e recuperação da saúde, a organização e o funcionamento dos serviços correspondentes e dá outras providências. Diário Oficial da União [serial on the internet], Brasília (1990 Sep 20 [cited 2018 apr 25]); Sec.1. Available from: http://www.planalto. gov.br/ccivil_03/leis/l8080.htm

24. Cordeiro RGF, Mello DR, Manso MEG, Nechio M, Carvalho W. Poder de polícia e as ações de vigilância sanitária. Integração [serial on internet]. 2006 [cited 2018 Apr 25];45:161-9. Available from: http://www.usjt.br/prppg/ revista/integracao/integracao_45.php. pdf

25. De Seta MH, Silva JAA. A gestão da vigilância sanitária. In: De Seta MH, Pepe VLE, Oliveira G0, organizers. Gestão e vigilância sanitária: modos de pensar e fazer. Rio de Janeiro: Fiocruz; 2006. p. 195-217.

26. Lucchesi G. A vigilância sanitária no Sistema Único de Saúde. In: De Seta MH, Pepe VLE, Oliveira G0, organizers. Gestão e vigilância sanitária: modos atuais do pensar e fazer. Rio de Janeiro: Fiocruz; 2006. p. 33-48.

27. Ferraro AHA, Costa EA, Vieira-da-Silva LM. Imagemobjetivo para a descentralização da vigilância sanitária em nível municipal. Cad Saúde Pública [serial on internet]. 2009 [cited 2018 Apr 25];25(10):2201-17. Available from: http://www.scielo.br/pdf/csp/v25n10/11.pdf
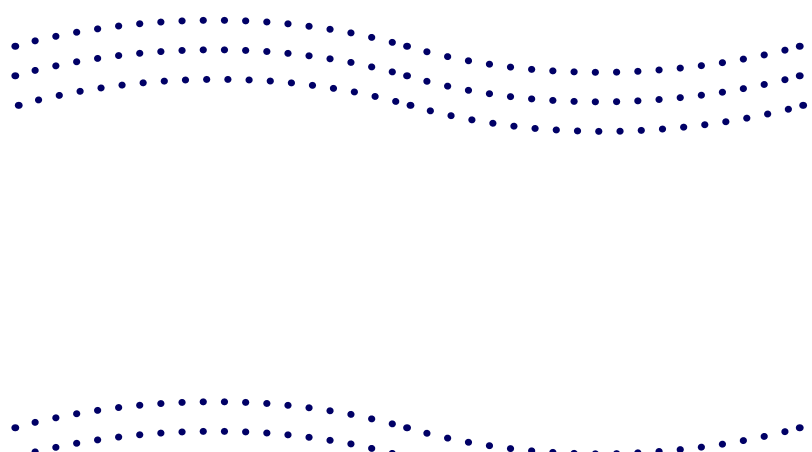
$\ldots \ldots \ldots \ldots \ldots \ldots \ldots \ldots \ldots$ $\ldots \ldots \ldots \ldots \ldots \ldots \ldots$ •..................

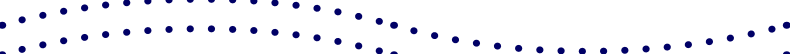
$\ldots \ldots \ldots \ldots \ldots \ldots \ldots \ldots$ ... 